\title{
Bronchobiliary fistula after hepatectomy: A case report and review of the literature
}

\author{
VASILIKI LAZAROU $^{1}$, DIMITRIOS MORIS ${ }^{2}$, ALEXANDROS PAPALAMPROS ${ }^{2}$, \\ DIAMANTIS I. TSILIMIGRAS ${ }^{2}$, GEORGIA-SOFIA KARACHALIOU ${ }^{2}$ and ATHANASIOS PETROU ${ }^{1}$
}

\author{
${ }^{1}$ Nicosia Surgical Department, Division of Hepatobiliary Pancreatic Surgery, Nicosia General Hospital, Nicosia 2029, Cyprus; \\ ${ }^{2}$ First Department of Surgery, Laikon General Hospital, University of Athens, Athens 11527, Greece
}

Received November 28, 2018; Accepted May 16, 2019

DOI: $10.3892 /$ mco.2019.1935

\begin{abstract}
Bronchobiliary fistula (BBF) is a rare complication following hepatectomy, and consists of an abnormal intercommunication between the biliary tract and bronchial tree. The management of this rare entity is challenging with limited current evidence to date on how to treat this condition. Herein, a case of BBF following a central hepatectomy and the successive steps of the management was presented. Fourteen months postoperatively, the patient presented to the Oncology Department complaining of new onset fever and expectoration. A computerized tomography scan revealed a BBF and the patient was subsequently referred to our department for further treatment. The surgical team decided that a further operation was required. Using the transabdominal approach, a communication between the initial intrahepatic collection and one inferior lobular bronchus was revealed. Transhiatal removal of fistula was performed with closure of the defect through the abdomen. There was no bile leak through the remaining liver parenchyma. Multidisciplinary management should be considered, taking into consideration the underlying pathology leading to this rare complication. Conservative treatment should be considered first, while surgical resection of the BBF remains an option when other therapies have failed. Surgeons should be aware of this rare complication bile duct injuries during hepatic operations can cause.
\end{abstract}

\section{Introduction}

First described by Peacock in 1850, a bronchobiliary fistula $(\mathrm{BBF})$ is a rare complication after hepatectomy, which consists of an abnormal intercommunication between the biliary tract and bronchial tree (1). This may occur due to an obstruction of the biliary tract, trauma or hepatic abscess. Especially in

Correspondence to: Dr Dimitrios Moris, First Department of Surgery, Laikon General Hospital, University of Athens, Agiou Thoma 17, Goudi, Athens 11527, Greece

E-mail: dimmoris@yahoo.com

Key words: bronchobiliary fistula, hepatectomy, complication endemic regions, hydatid or amebic disease of the liver are common causes of BB $(2,3)$. The classic clinical presentation includes cough producing yellow sputum, known as bilioptysis, which represents a pathognomonic sign of BBF (4). Of note, $\mathrm{BBF}$ is associated with high morbidity and mortality rates. The management of this rare entity is challenging with limited current evidence to date on how to treat this condition (5). Herein, we present a case of BBF following a central hepatectomy and the successive steps of the management. In addition, we sought to conduct a review the literature to summarize all the available evidence regarding post-hepatectomy BBFs.

\section{Case presentation}

A 64-year-old Caucasian male was diagnosed with adenocarcinoma of the rectum in 2012 for which he underwent low anterior resection with adjuvant chemotherapy (FOLFOX). The histological report of the specimen revealed a moderate to poorly differentiated adenocarcinoma of the rectum with T3c invasion of the bowel wall and metastases to mesorectal lymph nodes (stage IIC). The patient was referred to the oncology department for further treatment. During a routine follow-up at three years, the computer tomography (CT) scan demonstrated an asymptomatic solitary hypoechoic lesion in segment VIII measuring approximately $5 \mathrm{~cm}$ in diameter (Fig. 1). Given the absence of other comorbidities, the multidisciplinary team decided that liver resection was appropriate.

During exploratory laparotomy, intraoperative findings with hepatic U/S confirmed a solitary lesion in segment VIII of the liver. A central hepatectomy was performed without any intraoperative complications and the immediate postoperative clinical course was uneventful. Histological report confirmed that the lesion was of metastatic nature, from poorly differentiated adenocarcinoma of colon, and the patient was referred to the oncology department.

Three months later, the patient was admitted under the care of the medical oncology team with a history of fatigue for two days, weight loss and fever up to $39^{\circ}$. A CT scan demonstrated a postoperative intrahepatic collection (Fig. $2 \mathrm{~A}$ ) and a $12 \mathrm{~F}$ drain was inserted by a radiologist with CT guidance. An endoscopic retrograde cholangiopancreatography (ERCP) was performed which demonstrated a bile leak, and a $9 \mathrm{~cm} 10 \mathrm{~F}$ stent was placed (Fig. 2B). The patient was discharged 20 days 
later with the drain in situ and was examined regularly in our outpatient clinic.

However, 14 months postoperatively, the patient presented to the oncology department complaining of new onset fever and expectoration. A chest $\mathrm{X}$ - ray was performed demonstrating atelectasis of the lower right lobe and was treated as suspected pneumonia. Given the patient previous history, an inflammatory tumor was included in the differential diagnosis. Although afebrile, the patient reported episodes of a productive cough with dark-yellow sputum, raising concerns for bronchobiliary fistula. The patient underwent a CT scan which confirmed the clinical suspicion and he was subsequently referred to our department for further treatment. Since the patient had a biliary stent in situ, the surgical team decided that a further operation was required. Using a transabdominal approach, a communication between the initial intrahepatic collection and one inferior lobular bronchus was demonstrated. Transhiatal removal of fistula was performed with closure of the defect through the abdomen (Fig. 3). There was no bile leak through the remaining liver parenchyma.

The postoperative course was uneventful with no further bilioptysis or other pulmonary symptoms. At radiological follow up one month postoperatively, a CT showed a postoperative biloma for which the patient underwent $\mathrm{CT}$ guided drainage with a $12 \mathrm{~F}$ catheter. A further ERCP revealed leakage and communication of the bile duct with the biloma which was drained and a stent was inserted. The patient was discharged 2 months after surgery and was examined regularly in the outpatient clinic. He was readmitted on a schedule to remove the plastic stent by ERCP. Currently, there are no signs of further bile leakage, BBF or pulmonary symptoms.

\section{Discussion}

BBP is an uncommon condition whose etiology can differ by geographical region; in developing countries echinococcal and amebic disease are the most common causes, whereas in developed countries trauma and biliary obstruction predominate (6). According to a recent systematic review, tumor is the most frequent cause $(32.3 \%)$ of BBF formation, followed by bile duct obstruction (30.8\%) (7). Other causes have also been identified, such as chronic pancreatitis, trauma and congenital malformation. The pathogenesis of fistula formation has not been completely understood yet, although increased pressure within the biliary tree and local inflammation appeared to be the two major factors that contribute to the development of BBF. In our case, intrahepatic abscess triggered the formation of adhesions between the diaphragm and the lung and was thought to be the cause of the BBF formation (4,8-10).

The clinical presentation is variable, and may include fever, irritating cough, jaundice, and abdominal pain. The pathognomonic feature is a productive cough of bile stained sputum $(7,11)$. Chest pain or episodes of dyspnea occur only in a minority of patients, while nausea, vomiting, portal hypertension and liver dysfunction are rarely found. In terms of diagnosis, CT imaging is usually the predominant modality or biliary scintigraphy with hepatic iminoacetic acid (HIDA) which demonstrates initial tracer activity in the liver which migrates into the chest cavity (12). BBF can also

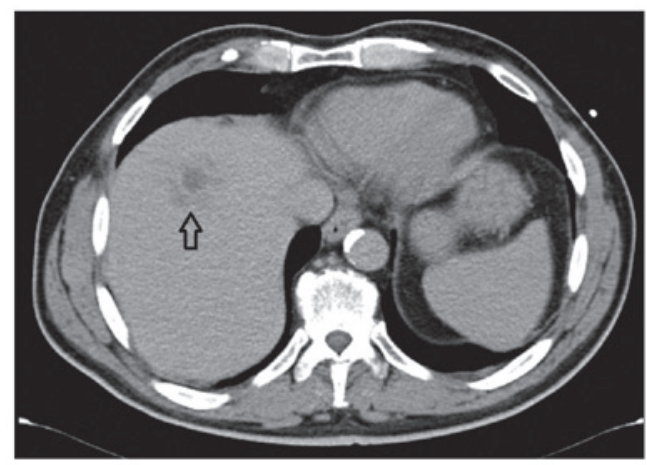

Figure 1. Computerized tomography scan demonstrating an asymptomatic solitary hypoechoic lesion in segment VIII measuring approximately $5 \mathrm{~cm}$ in diameter (arrow).

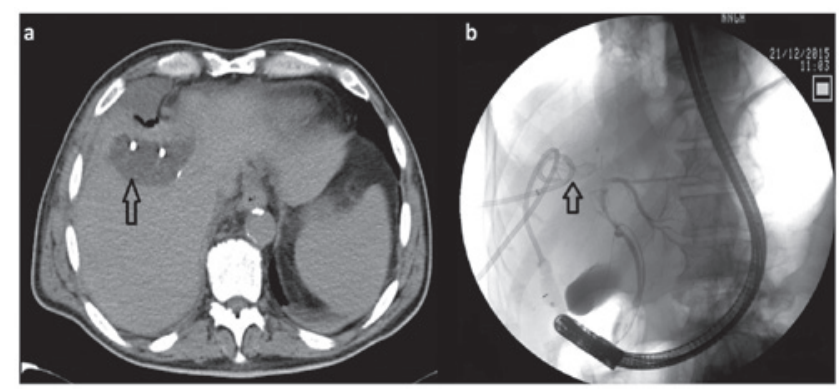

Figure 2. (A) A CT scan demonstrated a postoperative intrahepatic collection and a $12 \mathrm{~F}$ drain was inserted by a radiologist with $\mathrm{CT}$ guidance (arrow). (B) An endoscopic retrograde cholangiopancreatography (ERCP) was performed, which demonstrated a bile leak (arrow), and a $9 \mathrm{~cm} 10 \mathrm{~F}$ stent was placed. CT, computerized tomography.
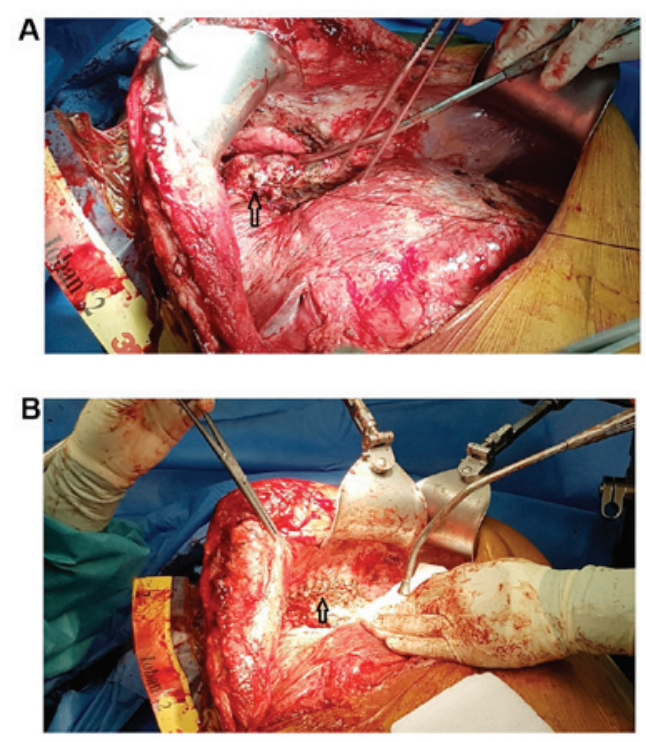

Figure 3. (A and B) Transhiatal removal of fistula was performed (arrow) with closure of the defect through the abdomen (arrow).

be diagnosed by interventional techniques, such as ERCP, percutaneous transhepatic cholangiography, bronchoscopy or fistulography $(4,13,14)$.

Currently, there are no guidelines on how to treat this rare complication with both conservative and surgical approaches 


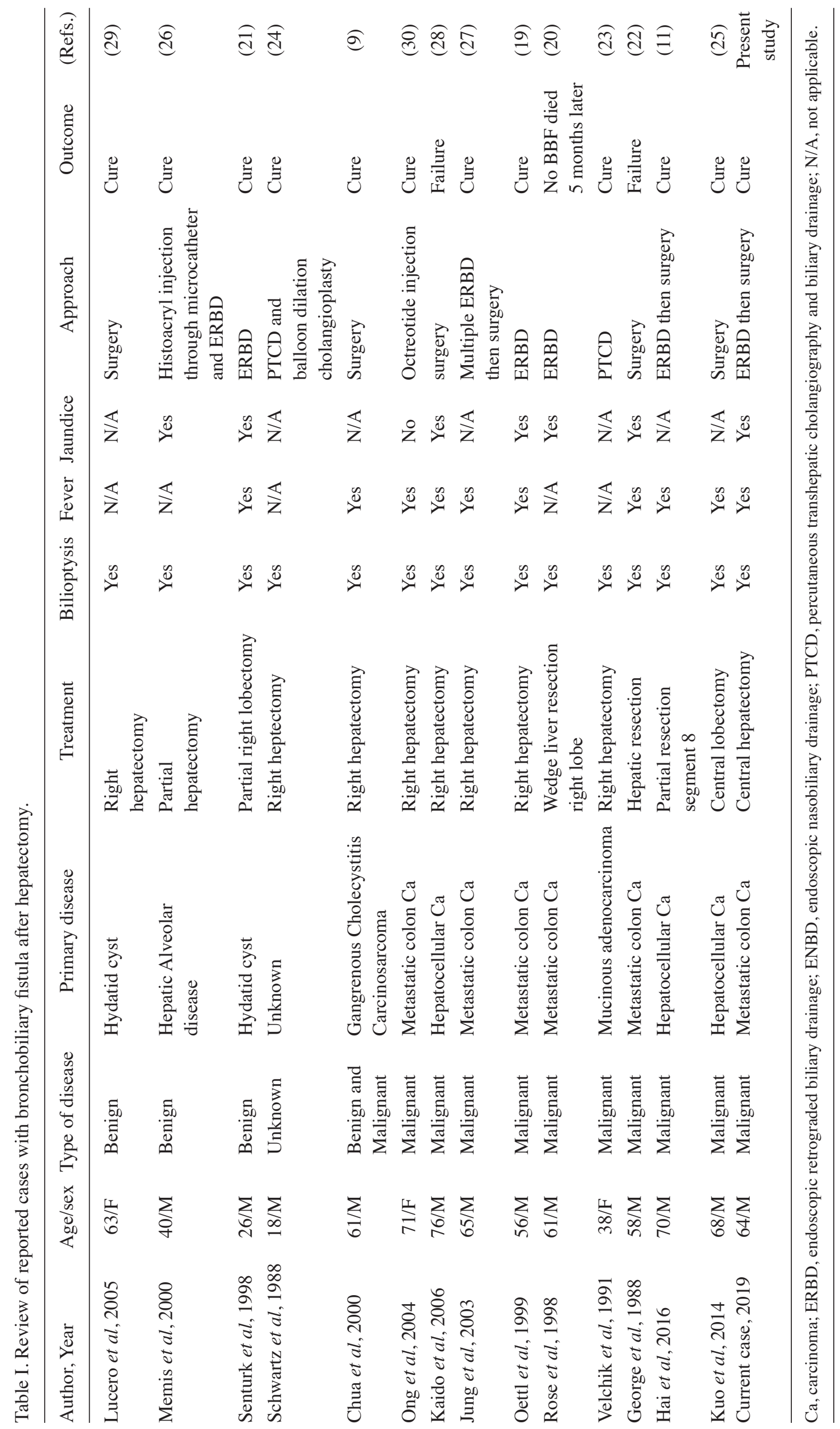


considered acceptable to date. Some authors suggest that BBF associated with benign causes should be treated conservatively; endoscopic retrograded biliary drainage (ERBD), endoscopic nasobiliary drainage (ENBD), percutaneous transhepatic cholangiography and biliary drainage (PTCD), and abscess drainage (15-17). Adjunct use of octreotide might have a role in some cases due to reports of successful resolution or reduction of symptoms with its use (18). On the other hand, surgical management should be considered in case BBF has developed in a background of tumor, trauma or obstruction and conservative therapy has previously failed (7). Operative exploration and repair of the initial injury is usually performed, whereas resection of the involved pulmonary area and removal of the fistula is advised in the form of thoracobiliary fistula decortication (18).

Table I summarizes a brief review of the literature on bronchobiliary fistulas after liver surgery for both benign and malignant diseases $(9,11,19-30)$.

Due to low incidence of BBF, there is no clear consensus on the treatment of this uncommon complication to date. Multidisciplinary management of such patients should be considered taking into consideration the underlying pathology leading to this rare complication. Conservative treatment should be considered first, while surgical resection of the BBF remains an option when other therapies have failed. Surgeons should have low suspicion of diagnosing and managing this complication after biliary tract operations.

\section{Acknowledgements}

Not applicable.

\section{Funding}

No funding was received.

\section{Availability of data and materials}

All data generated or analyzed during the present study are included in this published article.

\section{Authors' contributions}

VL, DM and APe were involved in the study conception and design. VL and APa contributed to the acquisition of data. VL, DM, DIT and GSK were involved in data analysis and interpretation. DM, DIT and GSK drafted the manuscript. APa and APe critically revised the manuscript.

\section{Ethics approval and consent to participate}

The study was approved by the Ethics Committee of Nicosia Hospital.

\section{Patient consent for publication}

Informed consent was obtained.

\section{Competing interests}

The authors declare that they have no competing interests.

\section{References}

1. Peacock TB: Case in which hydatids were expectorated, and one of suppuration in a hydatid cyst of the liver communicating with the lungs. Edinb Med Surg J 74: 33-46, 1850.

2. Mantonakis E, Papalampros A, Moris D, Dimitrokallis N, Sakarellos P, Griniatsos J and Felekouras E: Radiofrequency energy in hepatic bed during partial cystectomy for hydatid liver disease: Standing out from the usual conservative surgical management. Gastroenterol Res Pract 2016: 1078653, 2016.

3. Moris DN, Mantonakis EI, Papalampros AE, Petrou AS and Felekouras ES: Pushing the frontiers of operative treatment of hydatid liver disease a step forward. Surgery 160: 818, 2016.

4. Gugenheim J, Ciardullo M, Traynor O and Bismuth $\mathrm{H}$ : Bronchobiliary fistulas in adults. Ann Surg 207: 90-94, 1988.

5. Janczak D, Zielińska D, Pawelczyk J, Dorobisz T, Garcarek J, Patrzałek D and Chabowski M: Embolizations of the hepatic tumors-two-year single center experience. Vojnosanitetski Pregled, 2017.

6. Jamal Y, Tombazzi C, Waters B and Ismail MK: Bronchobiliary fistula in a cirrhotic patient: A case report and review of the literature. Am J Med Sci 335: 315-319, 2008.

7. Liao GQ, Wang H,Zhu GY,Zhu KB,LvFX and Tai S: Management of acquired bronchobiliary fistula: A systematic literature review of 68 cases published in 30 years. World J Gastroenterol 17: 3842-3849, 2011.

8. Akazawa S, Omagari K, Amenomori M, Nishiyama H, Mizuta Y and Kohno S: Bronchobiliary fistula associated with intrahepatic biloma after transcatheter arterial chemoembolization for hepatocellular carcinoma. J Hepatol 40: 1045-1046, 2004.

9. Chua HK, Allen MS, Deschamps C, Miller DL and Pairolero PC Bronchobiliary fistula: Principles of management. Ann Thorac Surg 70: 1392-1394, 2000.

10. Baudet JS, Medina A, Moreno A, Navazo L, Avilés J and Soriano A: Bronchobiliary fistula secondary to ruptured hepatocellular carcinoma into the bile duct. J Hepatol 41: 1066-1067, 2004.

11. Hai S, Iimuro Y, Hirano T, Suzumura K, Yada A and Fujimoto J: Bronchobiliary fistula caused after hepatectomy for hepatocellular carcinoma: A case report. Surg Case Rep 2: 147, 2016.

12. Andalkar L, Trow TK, Motroni B and Katz DS: Bronchobiliary fistula as a complication of liver metastases: Diagnosis by HIDA scan. Clin Nucl Med 29: 289-291, 2004.

13. Hibi T, Sakamoto Y, Asamura H, Tochigi N, Ojima H, Shimada K, Sano T and Kosuge T: Successful resection of hepatocellular carcinoma with bronchobiliary fistula caused by repeated transcatheter arterial embolizations: Report of a case. Surg Today 37: 154-158, 2007.

14. Cropper LD Jr, Gold RE and Roberts LK: Bronchobiliary fistula: Management with percutaneous catheter drainage of a subphrenic abscess. J Trauma 22: 68-70, 1982.

15. Yilmaz U, Sahin B, Hilmioglu F, Tezel A, Boyacioglu S and Cumhur T: Endoscopic treatment of bronchobiliary fistula: Report on 11 cases. Hepatogastroenterology 43: 293-300, 1996.

16. Singh B, Moodley J, Sheik-Gafoor MH, Dhooma N and Reddi A: Conservative management of thoracobiliary fistula. Ann Thorac Surg 73: 1088-1091, 2002.

17. Ertuğrul I, Köklü S, Köksal AS, Coban S, Başar O, Ibiş M and Sahin B: Treatment of bronchobiliary fistula due to an infected hydatid cyst by a nonsurgical approach. Dig Dis Sci 49: 1595-1597, 2004.

18. Crnjac A, Pivec V and Ivanecz A: Thoracobiliary fistulas: Literature review and a case report of fistula closure with omentum majus. Radiol Oncol 47: 77-85, 2013.

19. Oettl C, Schima W, Metz-Schimmerl S, Függer R, Mayrhofer T and Herold CJ: Bronchobiliary fistula after hemihepatectomy: Cholangiopancreaticography, computed tomography and magnetic resonance cholangiography findings. Eur J Radiol 32: 211-215, 1999.

20. Rose DM, Rose AT, Chapman WC, Wright JK, Lopez RR and Pinson CW: Management of bronchobiliary fistula as a late complication of hepatic resection. Am Surg 64: 873-876, 1998.

21. Senturk H, Mert A, Ersavasti G, Tabak F, Akdogan M and Ulualp K: Bronchobiliary fistula due to alveolar hydatid disease: Report of three cases. Am J Gastroenterol 93: 2248-2253, 1998.

22. George TK and Carignan JR: Bronchobiliary fistula after hepatic resection for metastatic colon cancer. J Surg Oncol 25: 198-200, 1984.

23. Velchik MG, Roth GM, Wegener W and Alavi A: Bronchobiliary fistula detected by cholescintigraphy. J Nucl Med 32: 136-138, 1991. 
24. Schwartz ML, Coyle MJ, Aldrete JS and Keller FS: Bronchobiliary fistula: Complete percutaneous treatment with biliary drainage and stricture dilation. Radiology 168: 751-752, 1988.

25. Kuo YS, Lee SC, Chang H, Hsieh CB and Huang TW: Thoracoscopic surgery for bronchobiliary fistula: A case report. J Cardiothorac Surg 9: 139, 2014.

26. Memis A, Oran I and Parildar M: Use of histoacryl and a covered nitinol stent to treat a bronchobiliary fistula. J Vasc Interv Radiol 11: 1337-1340, 2000.

27. Jung SI, Goo JM, Han JK, Jang JY, Lee KU, Lee KH and Im JG: Recurrent bronchobiliary fistula: Unsuccessful management with repeated insertion of metallic biliary stent. J Vasc Interv Radiol 14: 1577-1579, 2003.
28. Kaido T, Kano M, Suzaki S, Yanagibashi K and Shiota M Bronchobiliary fistula after hepatectomy for hepatocellular carcinoma. Dig Dis Sci 51: 1117-1121, 2006.

29. Lucero Pizones JA, Iglesias López A, Alcázar Iribarren Marín M and Márquez Galán JL: Bronchobiliary fistula secondary to biliary stricture after hepatectomy. Rev Esp Enferm Dig 97: 135-136, 2005 (In English, Spanish).

30. Ong M, Moozar K and Cohen LB: Octreotide in bronchobiliary fistula management. Ann Thorac Surg 78: 1512-1513, 2004 